\title{
Intimate Partner Violence Concerns During COVID-19 Pandemic
}

\author{
Mehran Zarghami (i] ${ }^{1,2}$, Munn-Sann Lye ${ }^{3,4}$, Jamshid Yazdani Charati (iD ${ }^{5,6}$ and Fatemeh Abdollahi ${ }^{5,7,{ }^{*}}$ \\ ${ }^{1}$ Department of Psychiatry, School of Medicine, Mazandaran University of Medical Sciences, Sari, Iran \\ ${ }^{2}$ Psychiatry and Behavioral Sciences Research Center, Addiction Institute, Mazandaran University of Medical Sciences, Sari, Iran \\ ${ }^{3}$ Formerly Department of Community of Health, Faculty of Medicine and Health Sciences, Universiti Putra Malaysia, Serdang, Malaysia \\ ${ }^{4}$ Faculty of Medicine and Health Sciences, Universiti Tunku Abdul Rahman, Jalan Sungai Long, Bandar Sungai Long, 43000 Kajang, Selangor, Malaysia \\ ${ }^{5}$ Health Sciences Research Center, Addiction Institute, Mazandaran University of Medical Sciences, Sari, Iran \\ ${ }^{6}$ Department of Diostatistic, Faculty of Health, Mazandaran University of Medical Sciences, Sari, Iran \\ ${ }^{7}$ Department of Public Health, Faculty of Health, Mazandaran University of Medical Sciences, Sari, Iran \\ "Corresponding author: Health Sciences Research Center, Addiction Institute, Mazandaran University of Medical Sciences, 18 KM Farah Abab Road, Payambar Azam Campus, \\ Postal Code: 48471-16548, Sari, Iran. Tell: +98-1133543085, Fax: +98-1133542473, Email: abdollahizagh@gmail.com
}

Received 2020 June 04; Accepted 2020 June 06.

Keywords: COVID-19, Intimate Partner Violence, Quarantine, Pandemic, Women

The ongoing pandemic of COVID-19 disease caused by SARS-CoV-2 emerged as a public health concern, having spread like a wild fire $(1,2)$. The burden of this disease, including economic, sociological, and psychological, is substantial and well documented in the literature (3-5). There are no licensed vaccines or therapeutics available as yet (6). Thus, a range of preventive measures from mitigation to containment is used by countries (1). Imposition of individuals to social distancing, school closures, business cessations, and travel restrictions by governments may not always keep individuals safe from this situation (7). Overly proactive management approaches and prolonged lockdown and quarantine measures could result in economic and psychosocial consequences $(2,3,8)$.

Isolated individuals and physical distancing recommendations could decrease accessibility to resources such as health care providers and social support. Job losses and unemployment have resulted in depriving individuals of vital livelihoods and healthcare benefits and are potential causes of psychological and economic stress $(1,9)$. Psychological consequences due to the quarantine measures range from frustration to severe depression and stressrelated disorders such as post-traumatic stress disorder (PTSD) $(3,4,10)$. A psychosocially disrupting response that has not gotten noteworthy attention is the increase in intimate partner violence (IPV) $(1,7)$.

Violence against women is one of the most shameful of human rights violations. It usually refers to physical, sexual, or psychological harm or suffering of the women. Globally, about one-third of women involved have experienced of violence by their intimate partners during their lifespan. It is identified as an important cause of women morbidity and mortality (11). Intimate partner violence has been linked to a variety of health impacts, including anxiety, depression (12), type 2 diabetes (13), reproductive health problems such as pregnancy and fetal complications, sexually transmitted diseases and unplanned pregnancy (14), cervical cancer (15), and tendencies toward addictions, and suicide (16). Every known stressor, loss of income, and isolation all can cause or worsen the danger of IPV at home (7). Quarantine related to the COVID-19 pandemic may impose restrictive social measures for individuals. Social isolation, decreased functions, surveillance, and controlling behaviors- all known IPV risk factors- are dramatically increased during such a situation $(7,17)$. Additionally, decreased community resources availability, psychological and economic stressors, such as job loss or decreased income, as well as alcohol abuse, are likely to overlap with IPV risk factors and can trigger a unique wave of $\operatorname{IPV}(1,7,9)$.

Related reports indicate an increase in the incidence of IPV due to quarantine. France, Brazil, and China indicated a $30 \%, 40 \%-50 \%$, and $300 \%$ increase in domestic violence reports during this period, respectively (7). Recently, a similar increase in IPV has been reported in other countries such as Spain, Australia, and the United States (18). The growing trend of raising IPV cases is likely to be continued through this pandemic and also, what we see may only represent a "tip of the iceberg" of victims $(1,7)$. At the time of the global pandemic of COVID-19, although being quarantined and left alone at home may protect abused women from the disease, community assistance and intervention are essential to reduce the impact of IPV on women and family members during this period. 
Community members should be informed about the rise in IPV during such quarantine. They can help by getting in touch with abused women constantly, supporting them and helping to find available information and support while adhering to distancing regulations. Getting support from family members and friends may be the measure of first choice for the abused women. However, giving this support becomes more difficult for them with quarantine and social distancing. Moreover, a number of cultural barriers, particularly in developing countries, make it difficult to get such support from close relatives. Some abused women may be reluctant to admit to being violated and exposing this matter or to deal with the issue since it is often a taboo in these societies (19).

All physicians and health care providers involved in COVID-19 should be informed about the increasing risk of IPV and its potential effect on women due to quarantine during this pandemic. They should be familiar with the symptoms of violence and be able to identify the abused women. They need to be trained on how they can help these women, communicate with them, and offer first-line support, including being a good listener, connecting them to support services, and having best practices to protect their safety $(1,9)$. Social networking is an approach that can help abused women during this period of the pandemic and isolation. It can provide an emergency contact, or a link to IPV services including SMS channels and internet-based platforms, which replace conventional inperson support $(1,20)$. Also, this raises public awareness and sensitizes them on this matter.

Finally, governments and policymakers should provide a supportive structure, including supportive services, shelter, and ways to make them accessible and also funding. These should be available during quarantine and continued response provided to vulnerable individuals even after the disaster is over (9). Partner violence often remains in the shadows in many societies. During this pandemic social, emotional, and economic stressors will likely be raised, and will probably continue for months to come. Failure to fully comply with these recommendations will have direct negative consequences for individuals, families, and communities for years to come.

\section{Footnotes}

Authors' Contribution: FA conceived, designed, and helped to draft the manuscript. MZ, MSL and JYC advised on the study design and revised the manuscript. All authors read and approved the final manuscript.

Conflict of Interests: There are no conflicts of interest.

Funding/Support: There was no supporting agent for this manuscript.

\section{References}

1. van Gelder N, Peterman A, Potts A, O'Donnell M, Thompson K, Shah N, et al. COVID-19: Reducing the risk of infection might increase the risk of intimate partner violence. EClinicalMedicine. 2020.

2. Evans O. Socio-economic impacts of novel coronavirus: The policy solutions. BizEcons Quarterly. 2020;7:3-12.

3. Huang Y, Zhao N. Generalized anxiety disorder, depressive symptoms and sleep quality during COVID-19 epidemic in China: a web-based cross-sectional survey. medRxiv. 2020.

4. Brooks SK, Webster RK, Smith LE, Woodland L, Wessely S, Greenberg $\mathrm{N}$, et al. The psychological impact of quarantine and how to reduce it: rapid review of the evidence. The Lancet. 2020.

5. Zarghami M. Psychiatric aspects of coronavirus (2019-nCoV) infection. Iran J Psychiatry Behav Sci. 2020;14(1). e102957.

6. Brüssow $H$. The novel coronavirus-a snapshot of current knowledge. Microbial Biotechnology. 2020;13(3):607-12.

7. Campbell AM. An increasing risk of family violence during the Covid19 pandemic: Strengthening community collaborations to save lives. Forensic Science International: Reports. 2020:100089.

8. Nacoti M, Ciocca A, Giupponi A, Brambillasca P, Lussana F, Pisano M, et al. At the epicenter of the Covid-19 pandemic and humanitarian crises in Italy: changing perspectives on preparation and mitigation. NEJM Catalyst Innovations in Care Delivery. 2020;1(2).

9. World Health Organization. COVID-19 and violence against women: what the health sector/system can do, 7 April 2020. World Health Organization; 2020.

10. Hawryluck L, Gold WL, Robinson S, Pogorski S, Galea S, Styra R. SARS control and psychological effects of quarantine, Toronto, Canada. Emerging Infectious Diseases. 2004;10(7):1206.

11. García-Moreno C, Pallitto C, Devries K, Stöckl H, Watts C, Abrahams $\mathrm{N}$. Global and regional estimates of violence against women: prevalence and health effects of intimate partner violence and non-partner sexual violence. World Health Organization; 2013.

12. Dillon G, Hussain R, Loxton D, Rahman S. Mental and physical health and intimate partner violence against women: A review of the literature. International journal of family medicine. 2013;2013.

13. Mason SM, Wright RJ, Hibert EN, Spiegelman D, Jun H, Hu FB, et al. Intimate partner violence and incidence of type 2 diabetes in women. Diabetes Care. 2013;36(5):1159-65.

14. Abdollahi F, Abhari FR, Delavar MA, Charati JY. Physical violence against pregnant women by an intimate partner, and adverse pregnancy outcomes in Mazandaran Province, Iran.Journal offamily \& community medicine. 2015;22(1):13.

15. Coker AL, Sanderson M, Fadden MK, Pirisi L. Intimate partner violence and cervical neoplasia. Journal of women's health $\&$ gender-based medicine. 2000;9(9):1015-23.

16. Bohn DK. Lifetime physical and sexual abuse, substance abuse, depression, and suicide attempts among Native American women. Issues in Mental Health Nursing. 2003;24(3):333-52.

17. Hagan E, Raghavan C, Doychak K. Functional isolation: Understanding isolation in trafficking survivors. Sexual Abuse. 2019:1079063219889060.

18. Peterman A, Potts A, O'Donnell M, Thompson K, Shah N, OerteltPrigione $S$, et al. Pandemics and violence against women and children. Center for Global Development Working Paper (in press). 2020.

19. Abdollahi F, Abhari FR, Charati JY, Rouhani S. Impact of psychological violence on pregnancy outcomes in a prospective study. Iranian journal of psychiatry and behavioral sciences. 2014;8(3):22.

20. Zapor $\mathrm{H}$, Wolford-Clevenger C, Johnson DM. The association between social support and stages of change in survivors of intimate partner violence. Journal of interpersonal violence. 2018;33(7):1051-70. 